\title{
A case-control study of risk factors for ischemic heart disease in patients attending tertiary care hospitals in India
}

\author{
Rachna Kapoorr ${ }^{1}$, Sheetal Vyas ${ }^{2}$, Pinkal Patel $^{3}$, Hemangi Mehta $^{4}$, Pooja Mehta ${ }^{5}$, Jinkal Modi ${ }^{6}$, Sruthi Nair \\ ${ }^{1}$ Associate Professor, ${ }^{2}$ Professor and Head, ${ }^{3}$ Tutor, ${ }^{4,5,6,7}$ MBBS students, Department of Community Medicine, AMC MET \\ Medical College, Ahmedabad, India.
}

\begin{abstract}
Ischemic heart disease (IHD) is the leading cause of both mortality and forgone healthy years of life among working -age adults (15-69 years) in South Asia. It is the leading cause of death in India and worldwide. For noncommunicable diseases (NCDs), common, modifiable and easily measurable risk factors could be reliably used to predict the future burden of the diseases and to measure the effectiveness of public health interventions. A casecontrol study was undertaken to examine the socio-demographic profile of IHD patients and to identify the risk factors in already diagnosed cases of IHD admitted in three tertiary care hospitals of Ahmedabad, India. We have included 100 cases and 100 controls who were group matched with the cases. The association of various risk factors with IHD was assessed. On univariate analysis it was found that 7 out of 8 risk factors were significantly associated with IHD. They are alcohol consumption (OR; 14.6, 95\% CI; 6.4-33.3), smoking (OR; 13.6, 95\% CI; 6.6-27.8), tobacco consumption in non-smoking form (OR;2.3, 95\% CI; 0.78-7.02), hypertension (OR; 6.5, 95\% CI; 3.4-12.3), Type 2 diabetes (OR; 4.5, 95\% CI; 2.4-8.7), obesity (OR; 9.7, 95\% CI; 4.9-19.1), sedentary lifestyle (OR; 3.8, CI; 1.8-8.4 ) and family history (OR; 5.3, 95\% CI; 2.8-9.9). This study identified the significance of alcohol, smoking, obesity, Type 2 diabetes, hypertension, sedentary lifestyle and family history in the outcome of IHD. This suggests that the increased cardiovascular risk among the urban population of Ahmedabad city may be preventable through lifestyle interventions along with the judicious use of medicines to attain optimal levels of blood pressure, lipids and glucose among the high risk population.
\end{abstract}

Keywords: IHD, Case-control study, Risk factors, Tertiary care hospitals, India.

\section{Introduction}

A total of 57 million deaths occurred in the world during 2008; 36 million $(63 \%)$ were due to non-communicable diseases (NCDs), principally cardiovascular diseases (CVD), diabetes, cancer and chronic respiratory diseases. ${ }^{1}$ NCDs are the most frequent causes of death in most countries in the Americas, the Eastern Mediterranean, Europe, South-East Asia and the Western Pacific. ${ }^{2}$ The leading causes of NCD deaths in 2008 were CVD (17 million deaths, or $48 \%$ of NCD deaths) - over $80 \%$ of cardiovascular and diabetes deaths occurred in low- and middleincome countries. ${ }^{3} \mathrm{NCD}$ deaths are projected to increase by $15 \%$ globally between 2010 and 2020 (to 44 million deaths). The greatest increases will be in the WHO regions of Africa, South-East Asia and the Eastern Mediterranean, where they will increase by over $20 \%$. The regions that are projected to have the greatest total number of NCD deaths in 2020 are South-East Asia (10.4 million deaths) and the Western Pacific (12.3 million deaths). ${ }^{4}$

Most NCDs are strongly associated and causally linked with four particular behaviors: tobacco use, physical inactivity, unhealthy diet and the harmful use of alcohol. ${ }^{5}$ These behaviors lead to four key metabolic/physiological changes: raised blood pressure, overweight/obesity, hyperglycemia and hyperlipidemia. In terms of attributable

\section{Practice Points}

- The burden of cardiovascular disease in the world is enormous and growing, and the majority of those affected are in developing countries.

- Ischemic heart disease (IHD) is the leading cause of death in India and worldwide.

- A number of modifiable risk factors are responsible for many premature or preventable deaths due to IHD.

- Alcohol consumption, smoking, tobacco consumption in non-smoking form, hypertension, type 2 diabetes, obesity, sedentary lifestyle and family history were found to be significantly associated with IHD.

- As many of the risk factors are modifiable and preventable, effective health promotion measures should be taken to reduce the significant proportion of premature morbidity and mortality due to IHD.

Correspondence: Dr. Rachna Kapoor, D7/1, DOS Housing Colony, Vikramnagar, Ambli Bopal Road, Behind ISKCON Temple, Ahmedabad- 380058, India, Email : drrk_kap@ymail.com. 
deaths, the leading NCD risk factor globally is raised blood pressure (to which 13\% of global deaths are attributed), followed by tobacco use $(9 \%)$, raised blood glucose $(6 \%)$, physical inactivity $(6 \%)$, and overweight and obesity $(5 \%){ }^{5}$

Ischemic heart disease (IHD) [or coronary heart disease (CHD)] is the leading cause of death in India and worldwide. ${ }^{6}$ Behavioral risk factors, including tobacco use, physical inactivity, and unhealthy diet, are responsible for about $80 \%$ of IHD and cerebrovascular disease. ${ }^{1}$ Worldwide, hypertension is estimated to cause 7.5 million deaths, about $12.8 \%$ of the total of all annual deaths ${ }^{5}$ which is a major risk factor for IHD and strokes (ischemic as well as hemorrhagic). ${ }^{7}$ Blood pressure levels have been shown to be positively and progressively related to the risk for stroke and coronary heart disease. ${ }^{8}$ In some age groups, the risk of CVD doubles for each incremental increase of $20 / 10 \mathrm{mmHg}$ of blood pressure, starting as low as $115 / 75 \mathrm{mmHg}$.

Worldwide, 2.8 million people die each year as a result of being overweight (including obesity) and an estimated 35.8 million $(2.3 \%)$ of global disability adjusted life years (DALYs) are caused by overweight or obesity. ${ }^{5}$ Overweight and obesity lead to adverse metabolic effects on blood pressure, cholesterol, triglycerides and insulin resistance. Risks of IHD, ischemic stroke and type 2 diabetes mellitus increase steadily with increasing body mass index (BMI), a measure of weight relative to height. ${ }^{10}$ Effective preventive and health promotion strategies are required at local and national levels to prevent mortality and improve quality of life of the people. ${ }^{11}$

With this in the background, a case-control study was conducted to assess the association of risk factors in patients already diagnosed with IHD attending three tertiary care hospitals of Ahmedabad city, India.

\section{Materials and methods}

A case-control study was carried out to assess the association of different risk factors of CVD in IHD patients in three tertiary care hospitals of Ahmedabad city: Lallubhai Govardhandas General Hospital (LG Hospital), Vadilal Sarabhai General Hospital (VS Hospital) and Sanjivni Hospital. One hundred patients, already diagnosed with IHD, (40 cases each from LG and VS hospitals; 20 cases from Sanjivni Hospital) were recruited and these were compared with 100 age and sex-matched patients as controls from the same hospitals (40 controls each from LG and VS hospitals; 20 controls from Sanjivni Hospital) who attended for conditions other than IHD.

The inclusion criteria were already diagnosed cases of IHD within last one year and who were above 40 years of age. Cardiovascular diseases encompassing IHD, angina pectoris, hypertension, myocardial infarction cerebrovascular disease (stroke), and congestive heart failure (excluding the organic and congenital CVD) were considered in this study.
The study was conducted from April 2012 to August 2012 (5 months). The data was collected by the medical students using a structured interview using a pretested questionnaire developed by the Faculty of Community Medicine Department of AMCMET Medical College, Ahmedabad.

The questionnaire was used to elicit information from the study participants for the following variables: demographic characteristics such as age, sex, religion, education and socio-economic status (SES); alcohol consumption; cigarette smoking; tobacco consumption in nonsmoking form; hypertension; Type 2 diabetes mellitus; obesity; sedentary lifestyle and family history of IHD. Informed consent was obtained from each respondent prior to the interview and physical examination. The association of these risk factors and IHD was analyzed using Epi Info software.

\section{Results}

A total of 100 cases and 100 controls above 40 years of age and who had suffered from IHD within last one year were assessed. Mean age of the cases and controls was 50.4 years and 49.7 years respectively. Overall, $21 \%$ cases and $23 \%$ controls belonged to the age group 60 years or above. The study population comprised of more number of males (cases 55; controls 57) and 24\% of the study participants among cases and $23 \%$ among controls were illiterate. More than half of the cases and controls (52\% and 56\% respectively) had secondary education and more than $70 \%$ of participants in both groups were Hindus ( $74 \%$ cases and $79 \%$ controls). Maximum number of respondents in both groups belonged to socio economic status II (cases $42 \%$ and controls $40 \%$ ) followed by SES status I (cases 38\% and controls $36 \%$ ) (Table 1).

Hypertension was found to be present in $62 \%$ of cases as against $20 \%$ in the controls and half of the cases had diabetes whereas in the control group only $18 \%$ had diabetes. Assessment of obesity was carried out based on the measurement of BMI. Obesity was present in $65 \%$ of cases while only $16 \%$ of the controls were obese. Both the groups were assessed for the lifestyle and it was observed that $90 \%$ of cases and $70 \%$ of controls had sedentary lifestyle. It was also found that $67 \%$ and $56 \%$ of cases had history of smoking and alcohol consumption respectively, while only $13 \%$ and $8 \%$ of the controls had history of smoking and alcohol intake. Approximately $11 \%$ of cases were non-smokers as compared to controls where it was 5\%. Positive family history of IHD was present in $60 \%$ of cases and $22 \%$ of controls.

Odds Ratio (OR) was calculated for all the above mentioned risk factors between cases and controls. It was observed that seven out of eight risk factors were significantly associated with IHD. They are alcohol consumption (OR; 14.6, 95\% CI; 6.4-33.3), smoking (OR; 13.6, 95\% CI; 6.6-27.8), hypertension (OR; 6.5, 95\% CI; 3.4-12.3), type 2 diabetes (OR; 4.5, 95\% CI; 2.48.7), obesity (OR; 9.7, 95\% CI; 4.9-19.1), sedentary 
lifestyle (OR; 3.8, CI; 1.8-8.4) and family history (OR; 5.3, 95\% CI; 2.8-9.9). However, for tobacco consumption in non-smoking form (OR; 2.3, CI; 0.78-7.02) in our study was not significantly associated with IHD (Table 2).

\section{Discussion}

The present study was designed as hospital-based casecontrol study to assess risk factors among IHD patients and it was found that alcohol consumption, smoking, tobacco consumption in non-smoking form, hypertension, type 2 diabetes, obesity, sedentary lifestyle and family history were significantly associated with IHD.

Demographic data of the study population revealed that mean age of the cases and controls was 50.4 and 49.7 years respectively which was slightly lower than average age of first-time heart attack sufferers in South Asia and in the rest of the world. ${ }^{1}$ However, Prabhakaran et $a l .{ }^{12}$ found higher age limits while assessing the cardiovascular risk factor prevalence among men in a large industry of northern India.

We found that more than half of the cases in our study were educated up to secondary level and above and approximately one-quarter of the case were illiterate. A study conducted by Deb \& Dasgupta ${ }^{13}$ found that a $29 \%$ participant was educated up to secondary level and above and $45 \%$ was illiterate. In another study, Prabhakaran et al. ${ }^{12}$ found $12.6 \%$ of participants who was illiterate.

A number of studies conducted in India found significant association of IHD with smoking, ${ }^{12-18}$ tobacco consumption in non-smoking form, ${ }^{13,15,16}$ hypertension, ${ }^{12-20}$ type 2 diabetes, ${ }^{12-20}$ obesity. ${ }^{13,16-18,20}$ In the present study, $67 \%$ of the IHD patients were smokers. The prevalence of smoking among cases was higher in our study as compared to other studies conducted in India ${ }^{12-18}$ which clearly strengthens the evidence that smoking is an established risk factor for IHD. The prevalence of hypertension and diabetes were higher in our study $(62 \%$ and $50 \%$ ) as compared to the other studies conducted in different states of India. ${ }^{12-20}$

Obesity was more prevalent in the current study $(65 \%$ among cases) when compared with the other studies
Table 1: Socio-demographic profile of respondents

\begin{tabular}{|c|c|c|}
\hline $\begin{array}{c}\text { Socio-demographic } \\
\text { variables }\end{array}$ & $\begin{array}{c}\text { Cases } \\
(n=100)\end{array}$ & $\begin{array}{c}\text { Controls } \\
(n=100)\end{array}$ \\
\hline \multicolumn{3}{|l|}{ Age group (years) } \\
\hline $40-50$ & 48 & 50 \\
\hline $51-60$ & 31 & 27 \\
\hline $61-70$ & 18 & 19 \\
\hline$>70$ & 03 & 4 \\
\hline Mean & 51.9 & 51.8 \\
\hline SD & 42.7 & 42.5 \\
\hline \multicolumn{3}{|l|}{ Sex } \\
\hline Male & 55 & 57 \\
\hline Female & 45 & 43 \\
\hline \multicolumn{3}{|l|}{ Religion } \\
\hline Hindu & 74 & 79 \\
\hline Muslim & 19 & 16 \\
\hline Christians & 07 & 05 \\
\hline \multicolumn{3}{|l|}{ Education } \\
\hline Graduate & 20 & 17 \\
\hline Higher Secondary & 02 & 05 \\
\hline Secondary & 30 & 34 \\
\hline Primary & 24 & 21 \\
\hline Illiterate & 24 & 23 \\
\hline \multicolumn{3}{|l|}{ Socioeconomic status } \\
\hline I & 38 & 36 \\
\hline II & 42 & 40 \\
\hline III & 16 & 18 \\
\hline IV & 2 & 06 \\
\hline $\mathrm{V}$ & 2 & 0 \\
\hline
\end{tabular}

conducted in India. ${ }^{13,16-18,20}$ The prevalence of consumption of tobacco in non-smoking form was only $11 \%$ among cases but was high in other studies conducted in India. ${ }^{13,15,16}$

The regional differences in various parameters in the different studies are interesting as we have collected the data from Ahmedabad which is in West India and comparisons are made from data from East ${ }^{13,19}$ North $^{12,15,16}$ and Southern regions ${ }^{18}$ of India.

Table 2: Risk factors of IHD

\begin{tabular}{|l|c|c|c|c|c|c|}
\hline \multirow{2}{*}{ Risk factors } & \multicolumn{2}{|c|}{ Cases } & \multicolumn{2}{c|}{ Controls } & \multirow{2}{*}{ Odd's ratio (CI) } & \multirow{2}{*}{$p$-value } \\
\cline { 2 - 5 } & Yes & No & Yes & No & & \\
\hline Alcohol & 56 & 44 & 08 & 92 & $14.6(6.4-33.3)$ & $<0.0001$ \\
\hline Smoking & 67 & 33 & 13 & 87 & $13.6(6.6-27.8)$ & $<0.0001$ \\
\hline Non-smoking & 11 & 89 & 05 & 95 & $2.3(0.78-7.02)$ & 0.19 \\
\hline Known case of hypertension & 62 & 38 & 20 & 80 & $6.5(3.4-12.3)$ & $<0.0001$ \\
\hline Known case of type 2 diabetes & 50 & 50 & 18 & 82 & $4.5(2.4-8.7)$ & $<0.0001$ \\
\hline Obesity & 65 & 35 & 16 & 84 & $9.7(4.9-19.1)$ & $<0.0001$ \\
\hline Sedentary activity & 90 & 10 & 70 & 30 & $3.8(1.8-8.4)$ & $<0.0007$ \\
\hline Family history & 60 & 40 & 22 & 78 & $5.3(2.8-9.9)$ & $<0.0001$ \\
\hline
\end{tabular}


The study has a number of limitations. Being a hospitalbased study the cases and control may not be the representative of the general population. As the study was carried out with undergraduate medical students, we deliberately included small sample size due to paucity of available time.

\section{Conclusion}

The burden of cardiovascular disease in the world is enormous and growing, and the majority of those affected are in developing countries. Ischemic heart disease is the leading cause of death in India and worldwide. The findings of present study suggest that a number of modifiable risk factors are responsible for many premature or preventable deaths due to IHD. Alcohol consumption, smoking, tobacco consumption in nonsmoking form, hypertension, type 2 diabetes, obesity, sedentary lifestyle and family history were found to be significantly associated with IHD. As many of the risk factors are modifiable and preventable, effective health promotion measures should be undertaken to reduce the significant proportion of premature morbidity and mortality due to IHD.

\section{References}

1. Alwan A, Maclean DR, Riley LM, d'Espaignet ET, Mathers CD, Stevens GA, et al. Monitoring and surveillance of chronic non-communicable diseases: progress and capacity in high-burden countries. Lancet, 2010, 376:1861-8.

2. WHO. The global burden of disease: 2004 update. Geneva: World Health Organization, 2008.

3. WHO. Comparative quantification of health risks: Global and regional burden of disease attributable to selected major risk factors. Geneva: World Health Organization, 2004.

4. WHO. Global status report on noncommunicable diseases 2010. Geneva: World Health Organization, 2011.

5. WHO. Global health risks: mortality and burden of disease attributable to selected major risks. Geneva: World Health Organization, 2009.

6. Huffman, MD. Coronary Heart Diseases in India. Center for Chronic Disease Control. http:// sancd.org/uploads/pdf/factsheet CHD.pdf (accessed June 2013)

7. Policy and action for cancer prevention. Food, nutrition, and physical activity: a global perspective. Washington, DC, World cancer research fund/American Institute for Cancer Research, 2009.

8. Whitworth JA. World Health Organization/ International Society of Hypertension statement on management of hypertension. J Hypertens, 2003, 21:1983-92.
9. Chobanian AV, Bakris GL, Black HR, Cushman WC, Green LA, Izzo JL Jr, Jones DW, Materson BJ, Oparil S, Wright JT Jr, Roccella EJ; National Heart, Lung, and Blood Institute Joint National Committee on Prevention, Detection, Evaluation, and Treatment of High Blood Pressure; National High Blood Pressure Education Program Coordinating Committee. The seventh report of the Joint National Committee on Prevention, Detection, Evaluation, and Treatment of High Blood Pressure: the JNC 7 report. JAMA, 2003, 289:2560-72.

10. WHO. The World Health Report: 2002: Reducing the risks, promoting healthy life. Geneva: World Health Organization, 2002.

11. Prabhakaran D, Yusuf S. Cardiovascular disease in India: Lessons learnt and challenges ahead. Indian J Med Res 2010;132:529-30.

12. D. Prabhakaran D, Shah P, Chaturvedi V, Ramakrishnan L, Manhapra A, K. Srinath Reddy KS. Cardiovascular risk factor prevalence among men in a large industry of northern India. Natl Med J India 2005.18(2): 59-65.

13. Deb S, Dasgupta A. A study on risk factors of cardiovascular diseases in an urban health centre of Kolkata. Indian J Community Med :2008.33 (4): 271-5.

14. Shah B, Prashant Mathur P. Surveillance of cardiovascular disease risk factors in India: The need \& scope . Indian J Med Res 2010.132: 63442 .

15. Gupta V, Yadav K, Anand K. Patterns of tobacco use across rural, urban, and urban-slum populations in a north Indian community. Indian $J$ Community Med 2010;35:245-51.

16. Gupta R, Sarna M, Rastogi P, Kaul V, Gupta VP. Association of obesity with coronary risk factors in the North Indian Bhatia community: Jaipur Heart Watch-3. Indian Heart J 2004; 56:646-52.

17. Bhagyalaxmi A, Atul T, Shikha J. Prevalence of Risk Factors of Non-communicable Diseases in a District of Gujarat, India. J Health Popul Nutr 2013; 31(1): 78-85.

18. Chow C, Cardona M, Raju PK, Iyengar S, Sukumar A, Raju R, et al. Cardiovascular disease and risk factors among 345 adults in rural India the Andhra Pradesh Rural Health Initiative. Int $J$ Cardiol 2007; 116:180-5.

19. Hazarika NC, Narain K, Biswas D, Kalita HC, Mahanta J. Hypertension in the native rural population of Assam. Natl Med J India 2004; 17 : 300-4.

20. Gupta R, Gupta VP, Sarna M, Bhatnagar S, Thanvi J, Sharma V, et al. Prevalence of coronary heart disease and risk factors in an urban Indian population: Jaipur Heart Watch-2. Indian Heart J 2002: 54:59-66. 